\title{
Differential expression of L-FABP and L-BABP between fat and lean chickens
}

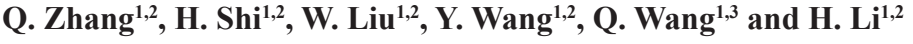 \\ ${ }^{1}$ Key Laboratory of Chicken Genetics and Breeding, Ministry of Agriculture, \\ Harbin, China \\ ${ }^{2}$ College of Animal Science and Technology, Northeast Agricultural University, \\ Harbin, China \\ ${ }^{3}$ Chongqing Academy of Animal Science, Chongqing, China \\ Corresponding authors: H. Li / Q. Wang \\ E-mail: lihui@neau.edu.cn / wangqigui@hotmail.com
}

Genet. Mol. Res. 12 (4): 4192-4206 (2013)

Received December 20, 2012

Accepted April 4, 2013

Published October 7, 2013

DOI http://dx.doi.org/10.4238/2013.October.7.5

\begin{abstract}
Liver fatty acid-binding protein (L-FABP) and liver bile acid-binding protein (L-BABP), in the liver intra-cytoplasm of chicken, are members of the fatty acid-binding protein subfamily. This study was designed to analyze and compare L-FABP and L-BABP expression levels between fat and lean lines in chicken liver tissue, and to determine the relationship between their expression and lipid metabolism. Realtime polymerase chain reaction (PCR) and Western blotting were used to detect the mRNA and protein expression in liver tissue between the lean and fat lines. Real-time PCR showed that L-FABP mRNA expression in fat male chickens was higher than that in lean male chickens at 2, 3, 4, 5,6 , and 10 weeks of age $(\mathrm{P}<0.05)$, and L-BABP mRNA expression in fat male chickens was higher than that in lean male chickens at 1,2, $3,4,8$, and 10 weeks of age $(\mathrm{P}<0.05)$. Western blotting showed that the L-FABP protein expression in fat male chickens was higher than that in lean male chickens at 3,5,6, and 7 weeks of age $(\mathrm{P}<0.05)$, and L-BABP protein expression in fat male chickens was higher than that in lean male chickens at $3,4,5$, and 6 weeks of age $(P<0.05)$. These results suggested that chicken L-FABP and L-BABP affect abdominal fat deposition through differences in their expression level, and the possible
\end{abstract}


mechanism is that a high expression level of L-FABP and L-BABP leads to a high lipogenesis rate and, ultimately, to lipid deposition.

Key words: L-FABP; L-BABP; Lipid deposition; Chicken

\section{INTRODUCTION}

Fatty acid-binding proteins (FABPs) belong to a superfamily of lipid-binding proteins that exhibit a high affinity for long-chain fatty acids and appear to function in the metabolism and intracellular transportation of lipids. They transport fatty acids from the plasma membrane to the sites of fatty acid oxidation and fatty acid esterification into triacylglycerols or phospholipids, or to the nucleus for possible regulatory functions. Tissues with high rates of fatty acid (FA) metabolism, such as intestine, liver, adipose, and muscle, have high levels of FABP that parallel FA uptake and utilization (Storch and Corsico, 2008). In avian species, lipogenesis takes place primarily in the liver, accounting for $95 \%$ of the de novo FA synthesis, and there is a general assumption that almost all the fat that accumulates in broiler adipose tissue is synthesized in the liver (Griffin et al., 1992). Two types of intracellular lipid-binding proteins are abundant in the avian liver; the liver fatty acid-binding protein (L-FABP) and the liver bile acid-binding protein (L-BABP), formerly called the liver "basic" fatty acid-binding protein (Lb-FABP) (Murai et al., 2009).

L-FABP was first discovered in the liver and expressed as an abundant gene product in differentiated enterocytes and hepatocytes (Gordon et al., 1985; Hertzel and Bernlohr, 2000; Murai et al., 2009). L-FABP has a broad fatty acid-binding specificity, especially with high affinity for long-chain polyunsaturated FAs. L-FABP also binds to other hydrophobic ligands, including cholesterol and bile acids (Norris and Spector, 2002; Newberry et al., 2009). Numerous studies of L-FABP have strongly suggested that it plays an important physiological role in hepatic lipid disposal and in the metabolic utilization of FAs (Atshaves et al., 2004, 2005; Martin et al., 2006, 2009; Wang et al., 2006; Newberry et al., 2009; Gao et al., 2010; He et al., 2012). It is also involved in partitioning of FAs to different metabolic pathways (Storch and Corsico, 2008) and delivery of peroxisome proliferator-activated receptor ligands to the nucleus and the resulting modulation of target-gene expressions (Wolfrum et al., 2001).

L-BABP is another kind of FABP in chicken liver, which shows higher amino acid sequence similarity to mammalian ileal-type FABP than that of L-FABP, and was formerly named liver basic type FABP (Sewell et al., 1989; Sams et al., 1991; Ceciliani et al., 1994). So far, L-BABP has never been found in mammalian species, but it has been identified and characterized in some vertebrates including fish, amphibians, reptiles, and birds (Ceciliani et al., 1994; Di Pietro et al., 1996, 1999, 2003; Córdoba et al., 1999; Denovan-Wright et al., 2000; Ko et al., 2004; Jordal et al., 2006). Recent research on the structure of the L-BABP crystal showed that the capacity of L-BABP for binding to long-chain fatty acids is weak, but is strong for bile acid (Schievano et al., 1994; Beringhelli et al., 2001; Guariento et al., 2008), which is consistent with the presumption that the main function of L-BABP is to transport bile acids rather than fatty acids in chicken (Nichesola et al., 2004; Capaldi et al., 2006).

Although the role of mammalian L-FABP in fatty acid metabolism and the binding characteristics of L-BABP have been well studied, the true physiological functions of these proteins in the avian have not been fully clarified. The current study was designed to detect the expression difference of the two FABPs in liver tissue between fat and lean birds, and to pro- 
vide the basic information for studying the role of these proteins in the regulation of fatty acids.

\section{MATERIAL AND METHODS}

\section{Experimental animals}

Ninety male chickens from the 11th generation population, and 60 male chickens from the 14th generation population of the Northeast Agricultural University broiler lines divergently selected for abdominal fat content were used in this study and their abdominal fat percentage (AFP) was calculated (Shi et al., 2010; Guo et al., 2011). The fat and lean chickens used were the offspring of the families with the highest AFP or the lowest AFP according to their slaughtered sibling information, respectively. All chickens were kept under the same environmental conditions and had free access to feed and water. Commercial corn-soybean-based diets that met all National Research Council requirements were provided to the birds. From hatching to 3 weeks, the birds received a starter feed $[210 \mathrm{~g} / \mathrm{kg}$ crude protein (CP) and $3000 \mathrm{kcal}$ metabolizable energy (ME)/kg], and from 4 weeks to slaughter, they were fed with a grower diet $(190 \mathrm{~g} /$ $\mathrm{kg} \mathrm{CP}$ and $3100 \mathrm{kcal} \mathrm{ME} / \mathrm{kg}$ ). All animal work was conducted according to the guidelines for the care and use of experimental animals established by the Ministry of Science and Technology of the People's Republic of China (Approval No. 2006-398), and was approved by the Laboratory Animal Management Committee of Northeast Agricultural University.

\section{Construction of chicken L-FABP and L-BABP eukaryotic expression vector}

Chicken abdominal liver tissue was collected and homogenized in $1 \mathrm{~mL}$ Trizol reagent (15596-026; Invitrogen, Carlsbad, CA, USA), and total RNA was extracted according to the directions of the manufacturer. The concentration of RNA was estimated by measuring the absorbance at 260 and $280 \mathrm{~nm}$ by UV spectrophotometry (Ultrospec 1000; Biochrom Ltd., Cambridge, UK). Reverse transcription was performed according to the instruction of the ImPromII $^{\mathrm{TM}}$ Reverse Transcriptase Kit (A3803; Promega, Madison, WI, USA). The coding regions of the chicken L-FABP and L-BABP genes were amplified by PCR using chicken L-FABP and L-BABP specific primers (LBF: 5'-cg gga ttc cg CAT AAT GGC ATT CAG TGG-3'; LBR: 5'-cg gcggecgc g TCA CAA AGA AGG TGA TCT G-3'; LFF: 5'-ga gga tcc ATG AGC TTC ACT GGA AAG TAC G-3'; LFR: 5'-cg ctc gag CAT GCA GGG TCT CTA GAT TCT CT-3'). The PCR products were digested with the corresponding restriction site endonucleases and then inserted into the pcDNA3.1 vector (Invitrogen) to construct the pcDNA3-L-FABP and pcDNA3-L-BABP plasmids.

\section{L-FABP and L-BABP antisera specificity analysis}

To detect the specificities of L-FABP and L-BABP antisera, the pcDNA3-L-FABP and pcDNA3-L-BABP plasmids were transfected into a DF1 cell line according to the directions for Lipofectamine 2000 (Invitrogen). Forty-eight hours after transfection, cultured DF1 cells were collected and washed with PBS. Aliquots of detergent-solubilized cells were separated by $10 \%$ SDS-PAGE and transferred to two Immun-Blot PVDF membranes (Millipore, Billerica, MA, USA). The two membranes obtained after protein transfer included total protein 
of chicken liver tissue, DF1 cells transfected with pcDNA3-L-FABP, DF1 cells (control), and DF1 cells transfected with pcDNA3-L-BABP.

After blocking of nonspecific binding, one of the membranes was immunoblotted with the rabbit anti-chicken L-FABP antiserum (1:3000) (Shi et al., 2008) for $1 \mathrm{~h}$ at room temperature, and the other membrane was immunoblotted with the rabbit anti-chicken L-BABP antiserum (1:3000) (Zhang et al., 2011) for $1 \mathrm{~h}$ at room temperature. After a wash with PBS containing $0.05 \%$ Tween-20, each membrane was immunoblotted with peroxidase-conjugated AffiniPure goat anti-rabbit IgG (H+L) (1:5000; ZB-2301; ZSGB-Bio, Beijing, China) for $1 \mathrm{~h}$ at room temperature. Finally, the immunoreactive protein on the membrane was visualized using enhanced chemiluminescence and was exposed to X-ray film (Bio-Rad, Hercules, CA, USA).

\section{mRNA expression levels of chicken L-FABP and L-BABP between fat and lean male chickens}

Chickens from the 14th generation population were slaughtered at 1, 2, 3, 4, 5, 6, 7, 8,9 , and 10 weeks of age, respectively, and liver tissues were isolated, immediately frozen in liquid nitrogen, and stored at $-80^{\circ} \mathrm{C}$. There were six samples for each week, with three chickens from the fat line and three chickens from the lean line, and the AFP was calculated. Total RNA was extracted from the chicken liver tissue by using a Trizol reagent kit (Invitrogen) according to the recommendations of the manufacturer. Reverse transcription was performed according to the directions of the TaKaRa RNA PCR Kit (version 3.0; TaKaRa). Real-time reverse-transcription PCR was used to detect L-FABP and L-BABP expression levels by using SYBR Premix Ex Taq (TaKaRa) with the L-FABP and L-BABP primers (LFF: 5'-GCA GAA TGG GAA TAA GTT-3'; LFR: 5'-TTG TAT GGG TGA TGG TGT-3'; LbF1: 5'-CCT CCA TAA TGG CAT TCA GT-3'; LbR1: 5'-AGT AGT AAT GTC AGC CTC TTT-3'), respectively. Chicken glyceraldehyde-3-phosphate dehydrogenase (GAPDH) was chosen as the internal reference and was detected with GAPDH primers (GF: 5'-AGA ACA TCA TCC CAG CGT-3'; GR: 5'-AGC CTT CAC TAC CCT CTT G-3'). Each reverse-transcribed reaction product (1 $\mu \mathrm{L}$ ) was amplified in a $20-\mu \mathrm{L}$ PCR system. Reaction mixtures were incubated in an ABI Prism 7500 sequence detection system (Applied Biosystems, Foster City, CA, USA) programmed to conduct 1 cycle at $95^{\circ} \mathrm{C}$ for $10 \mathrm{~s}$ and 40 cycles at $95^{\circ} \mathrm{C}$ for $5 \mathrm{~s}$ and $60^{\circ} \mathrm{C}$ for $34 \mathrm{~s}$. Dissociation curves were analyzed by the Dissociation Curve 1.0 software (Applied Biosystems) for each PCR to detect and eliminate possible primer-dimer artifacts. Results of real-time PCR were expressed as the relative quantity of L-FABP/GAPDH and L-BABP/GAPDH, respectively.

\section{Protein expression levels of chicken L-FABP and L-BABP between fat and lean male chickens}

Chickens were slaughtered at $2,3,4,5,6,7,8,9$, and 10 weeks of age (11th generation population) and at $1,2,3,4,5,6,7,8,9$, and 10 weeks of age (14th generation population), respectively, and liver tissues were isolated, immediately frozen in liquid nitrogen, and stored at $-80^{\circ} \mathrm{C}$. For the 11th generation population, there were 10 samples for each week, with five chickens from the fat line and five chickens from the lean line, and the AFP was calculated. Samples from the 14th generation population were the same as those used for the detection of mRNA expression level.

Livers were dissected and washed in ice-cold PBS, minced, and homogenized at $4^{\circ} \mathrm{C}$ in ice- 
cold radioimmunoprecipitation assay buffer $(150 \mathrm{mM} \mathrm{NaCl}, 50 \mathrm{mM}$ Tris-HCl, $\mathrm{pH}$ 7.5, 1\% NP40, $0.1 \%$ SDS, and $0.5 \%$ sodium deoxycholate) with the addition of the protease inhibitor phenylmethylsulfonyl fluoride (BY12203; Sigma, St. Louis, MO, USA), and then centrifuged at $2300 \mathrm{xg}$ for 20 min at $4^{\circ} \mathrm{C}$ to obtain total protein. The total protein was mixed with standard SDS-PAGE gelloading buffer, heated at $100^{\circ} \mathrm{C}$ for $5 \mathrm{~min}$, and then separated by $12 \%$ SDS-PAGE and transferred to an Immun-Blot polyvinylidene fluoride membrane (Millipore, Billerica, MA, USA). For each sample, $40 \mu \mathrm{g}$ total protein was used to analyze the expression levels of L-FABP, L-BABP, and GAPDH. L-FABP and L-BABP expression levels were analyzed using the L-FABP and L-BABP antisera and peroxidase-conjugated AffiniPure goat anti-rabbit IgG (H+L) (ZB-2301; ZSGB-Bio). Mouse anti-chicken GAPDH antibody (AG019; Beyotime Institute of Biotechnology, China) and peroxidase-conjugated AffiniPure goat anti-mouse IgG $(\mathrm{H}+\mathrm{L})$ (ZDR-5307; ZSGB-Bio) were used to detect GAPDH. Immunoreactive protein levels were determined semiquantitatively by densitometric analysis, using a laboratory imaging and analysis system (CA 91786; UVP, Upland, CA, USA). Results were expressed as the relative quantity of L-FABP/GAPDH and L-BABP/GAPDH.

\section{Statistical analysis}

Data from mRNA and protein quantification from each of the 11th and 14th generation populations were subjected to the $t$-test. The mRNA and protein quantification integrated data from the 11th and 14th generation populations were analyzed by the GLM procedure of SAS version 6.12 (SAS Institute Inc., Cary, NC, USA). Data are reported as means \pm SD. Difference was considered significant at $\mathrm{P}<0.05$, unless otherwise specified.

\section{RESULTS}

\section{Specificity of L-FABP and L-BABP antisera}

Western blot analysis showed chicken L-FABP to be visible as a band of about $14 \mathrm{kDa}$, both in the DF1 cells transfected with pcDNA3-L-FABP and in chicken liver tissue, but it showed no signal in the DF1 cells transfected with pcDNA3-L-BABP (Figure 1A). The L-BABP protein was also identified by its specific antiserum. It was visible as a band of approximately $12 \mathrm{kDa}$, both in the DF1 cells transfected with pcDNA3-L-BABP and in chicken liver tissue (Figure 1B). These results showed that each of the antisera can specifically recognize its corresponding protein.

\section{mRNA expression differences of L-FABP and L-BABP between fat and lean lines}

Real-time reverse-transcription PCR was used to detect L-FABP and L-BABP mRNA expression in liver tissue between fat and lean chickens. The results showed that there was significant difference in the mRNA expression of L-FABP between fat and lean chickens. The mRNA expression levels of fat chickens were much higher than those of lean chickens at 2, 3, 4, 5, 6, and 10 weeks of age (Figure 2). A joint analysis across weeks showed that the L-FABP mRNA expression in fat lines was 1.69-fold $(\mathrm{P}<0.05)$ that of lean lines. L-BABP mRNA expression was also significantly different between fat and lean chickens, with expression in fat chickens being much higher at 1, 2, 3, 4, 8, and 10 weeks of age (Figure 3). A joint analysis across weeks showed that the L-BABP mRNA expression level of fat lines was 1.45 -fold $(\mathrm{P}<0.05)$ that of lean lines. 


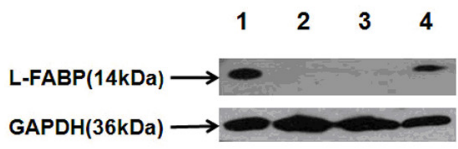

A

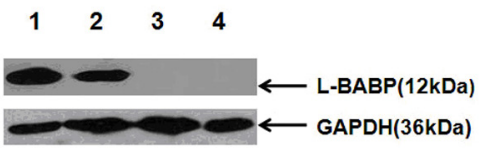

B

Figure 1. Specificity analysis of L-FABP and L-BABP antiserum by Western blot. A. Immunoblotted with the rabbit anti-chicken L-FABP antiserum (1:3000); B. immunoblotted with the rabbit anti-chicken L-BABP antiserum (1:2000). Lane $1=$ Chicken liver proteins; lane 2 = total protein of DF1 transfected with $\mathrm{pcDNA3} / \mathrm{L}-\mathrm{BABP}$ plasmid; lane 3 = total protein of normal DF1; lane 4 = total protein of DF1 transfected with pcDNA3/L-FABP plasmid.

\section{L-FABP mRNA expression level between}

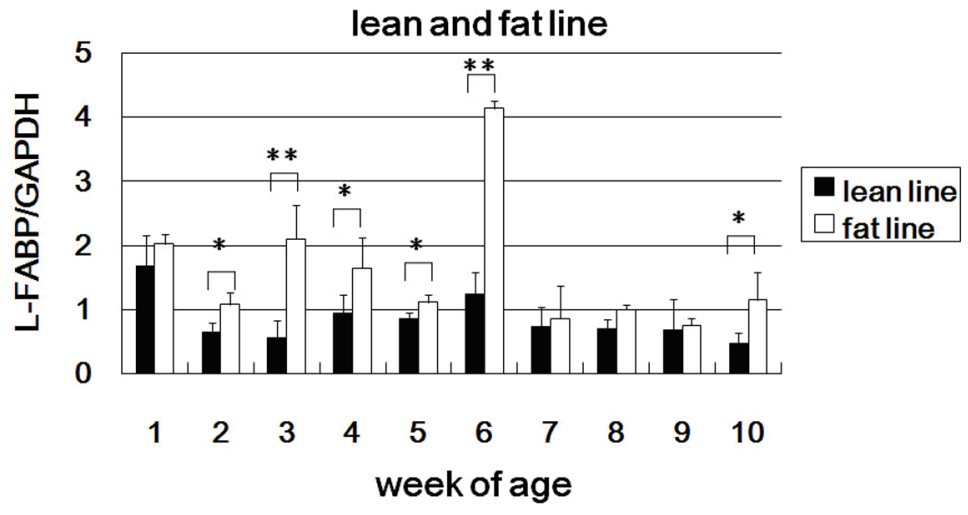

Figure 2. Analysis of liver fatty acid-binding protein (L-FABP) mRNA expression level in chicken liver tissues between fat and lean males for 14th generation population. Results are reported as means $\pm \mathrm{SD}(\mathrm{N}=3)$. $* \mathrm{P}<0.05$, significant difference. GAPDH = glyceraldehyde 3-phosphate dehydrogenase.

\section{L-BABP mRNA expression level between}

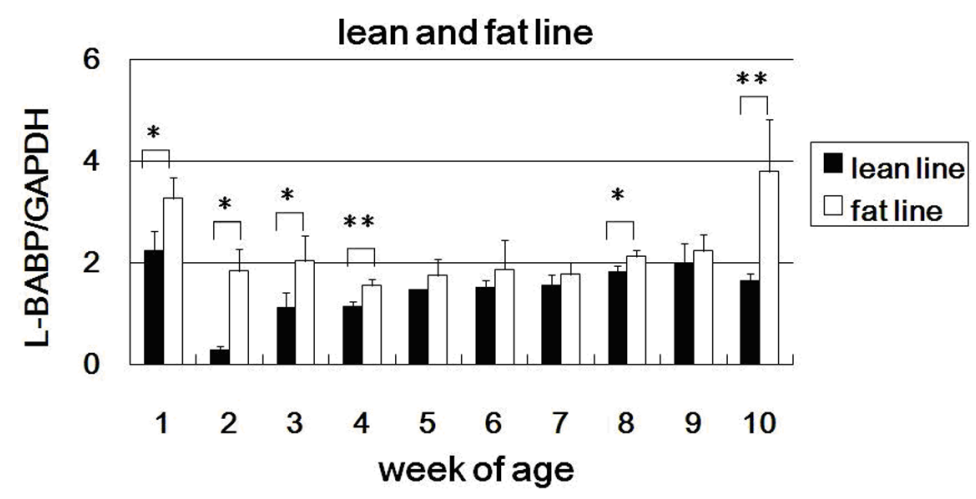

Figure 3. Analysis of liver bile acid-binding protein (L-BABP) mRNA expression level in chicken liver tissues between fat and lean males for 14th generation population. Results are reported as means $\pm \mathrm{SD}(\mathrm{N}=3) . * \mathrm{P}<0.05$, significant difference. GAPDH = glyceraldehyde 3-phosphate dehydrogenase. 


\section{Protein expression levels of L-FABP between fat and lean lines}

L-FABP protein expression was detected by western blot analysis (Figure 4). The results showed that L-FABP expression in fat chickens was higher than that in lean chickens at 7 weeks of age $(\mathrm{P}<0.05)$, but was lower at 9 weeks of age $(\mathrm{P}<0.05)$. Differences at other ages were found to be not significant in the 11th generation population (Figure 5). In the 14th generation, western blot results showed that there was a significant difference of L-FABP protein in liver tissue between fat and lean chickens. L-FABP expression in fat chickens was higher than that in lean chickens at $3,5,6,7$, and 10 weeks of age $(\mathrm{P}<0.05)$. For the other ages, no significant difference was detected (Figure 6 and 7). Combined results of the 11th and 14th generation populations showed that there was a significant difference of L-FABP protein in liver tissue between fat and lean chickens. The L-FABP expression in fat chickens was higher than that in lean chickens at 3,5,6, and 7 weeks of age $(\mathrm{P}<0.05)$ (Figure 8$)$. A joint analysis across weeks and generations showed that the L-FABP protein expression in fat lines was 1.16 -fold $(\mathrm{P}<0.05)$ that of lean lines.

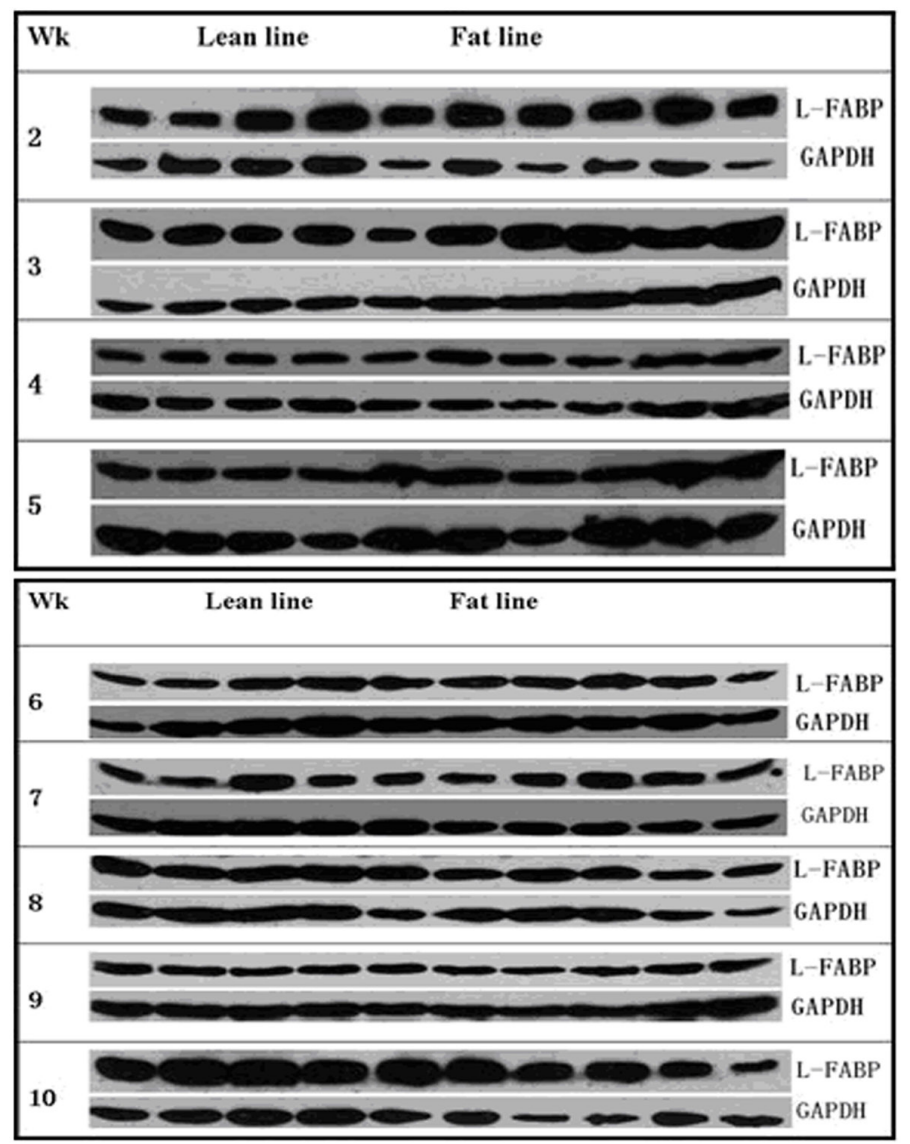

Figure 4. Western blot of liver fatty acid-binding protein (L-FABP) in chicken liver tissues between fat and lean males for 11 th generation population. $\mathrm{Wk}=$ week of age; GAPDH = glyceraldehyde 3-phosphate dehydrogenase. 


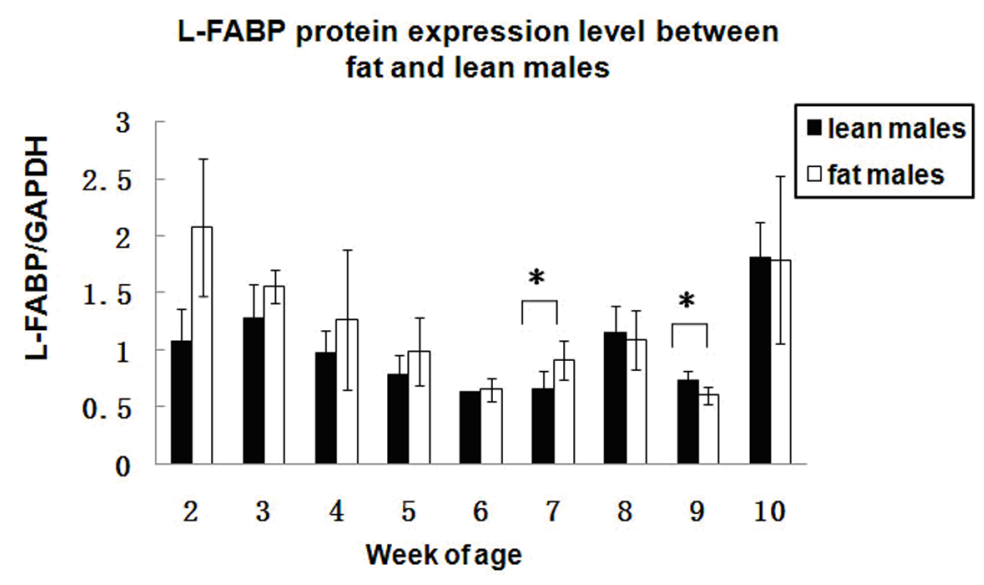

Figure 5. Analysis of liver fatty acid-binding protein (L-FABP) in chicken liver tissues between fat and lean males for 11th generation population. Results are reported as means $\pm \mathrm{SD}(\mathrm{N}=5)$. ${ }^{*} \mathrm{P}<0.05$, significant difference. GAPDH = glyceraldehyde 3-phosphate dehydrogenase.

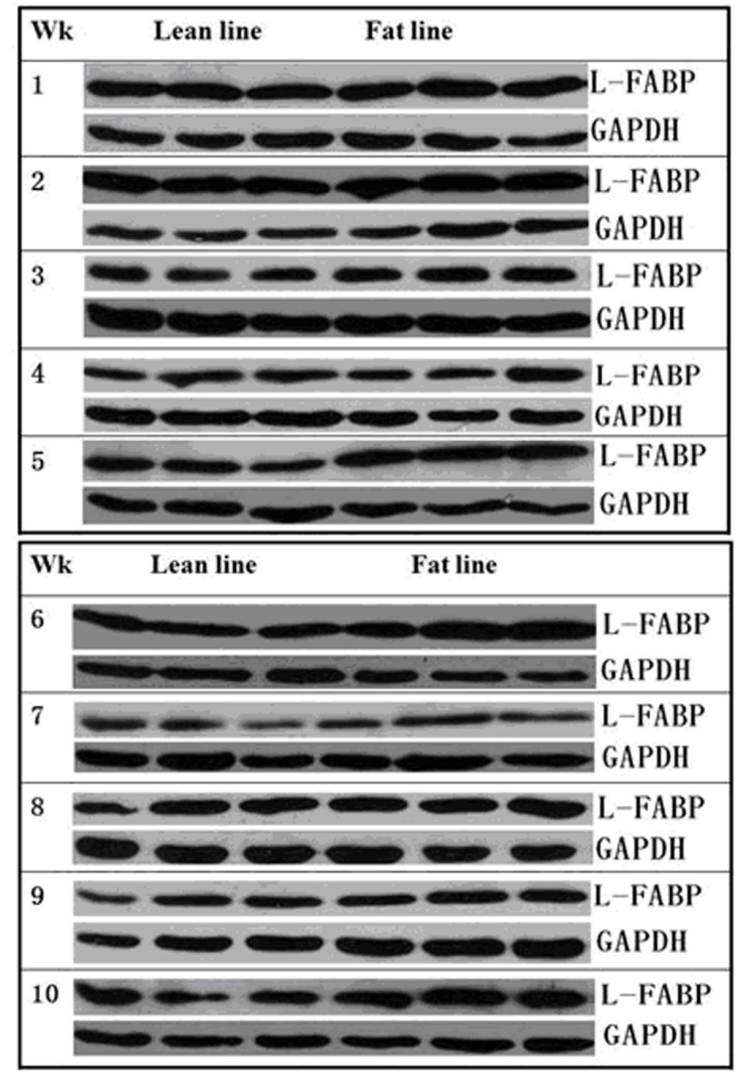

Figure 6. Western blot of liver fatty acid-binding protein (L-FABP) in chicken liver tissues between fat and lean males for 14th generation population. Wk = week of age; GAPDH = glyceraldehyde 3-phosphate dehydrogenase. 


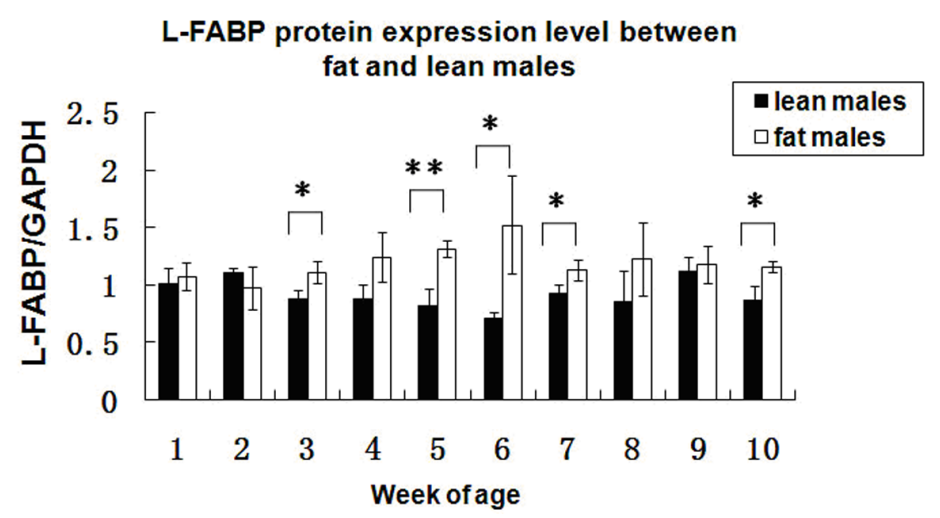

Figure 7. Analysis of liver fatty acid-binding protein (L-FABP) in chicken abdominal fat tissues between fat and lean males for 14th generation population. Results are reported as means $\pm \mathrm{SD}(\mathrm{N}=3)$. ${ }^{*} \mathrm{P}<0.05$, significant difference. GAPDH = glyceraldehyde 3-phosphate dehydrogenase.

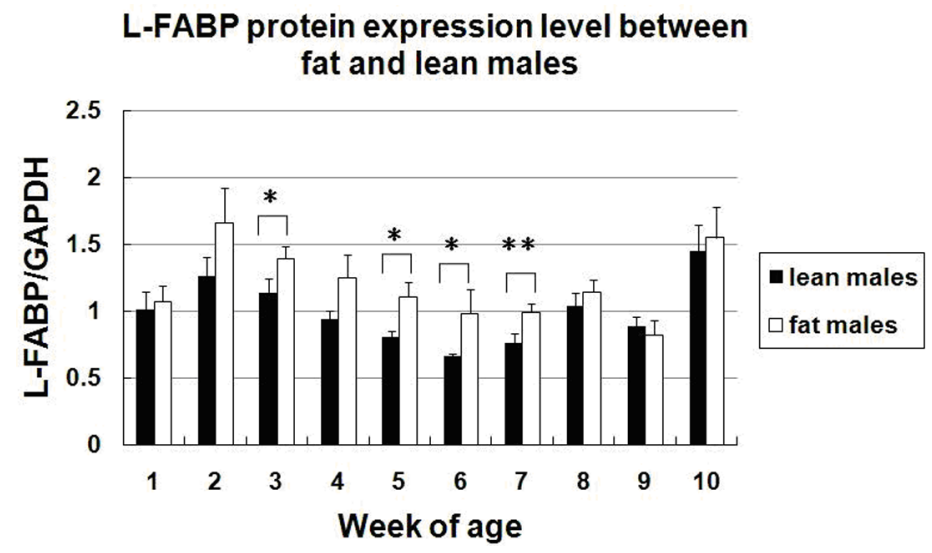

Figure 8. Analysis of liver fatty acid-binding protein (L-FABP) in chicken liver tissues between fat and lean males for 11th and 14th generation population. Results are reported as means $\pm \mathrm{SD}(\mathrm{N}=8) .{ }^{*} \mathrm{P}<0.05$, significant difference. GAPDH = glyceraldehyde 3-phosphate dehydrogenase.

\section{Protein expression levels of L-BABP between fat and lean lines}

L-BABP protein expression was detected by western blot analysis (Figure 9). The results showed that the L-BABP protein expression in fat chickens was higher than that those in lean chickens at 3,4 , and 6 weeks of age $(\mathrm{P}<0.05)$, but the expression levels in fat chickens were lower than those in lean chickens at 10 weeks of age. There was no significant difference at the other time points in the 11th generation population (Figure 10). In the 14th generation, the L-BABP protein expression in fat chickens was higher than that in lean chickens at 4 and 8 weeks of age $(\mathrm{P}<0.05)$, but with no significant difference at the other times (Figure 11 and 12). The combined results of the 11th and 14th generations showed that there was significant difference in L-BABP protein in liver tissue between fat and lean chickens, with the L-BABP 
expression in fat chickens being higher than that in lean chickens at 3, 4, 5, and 6 weeks of age $(\mathrm{P}<0.05)$ (Figure 13). A joint analysis across weeks and generations showed that the L-BABP protein expression in fat lines was 1.21 -fold $(\mathrm{P}<0.05)$ that of lean lines.

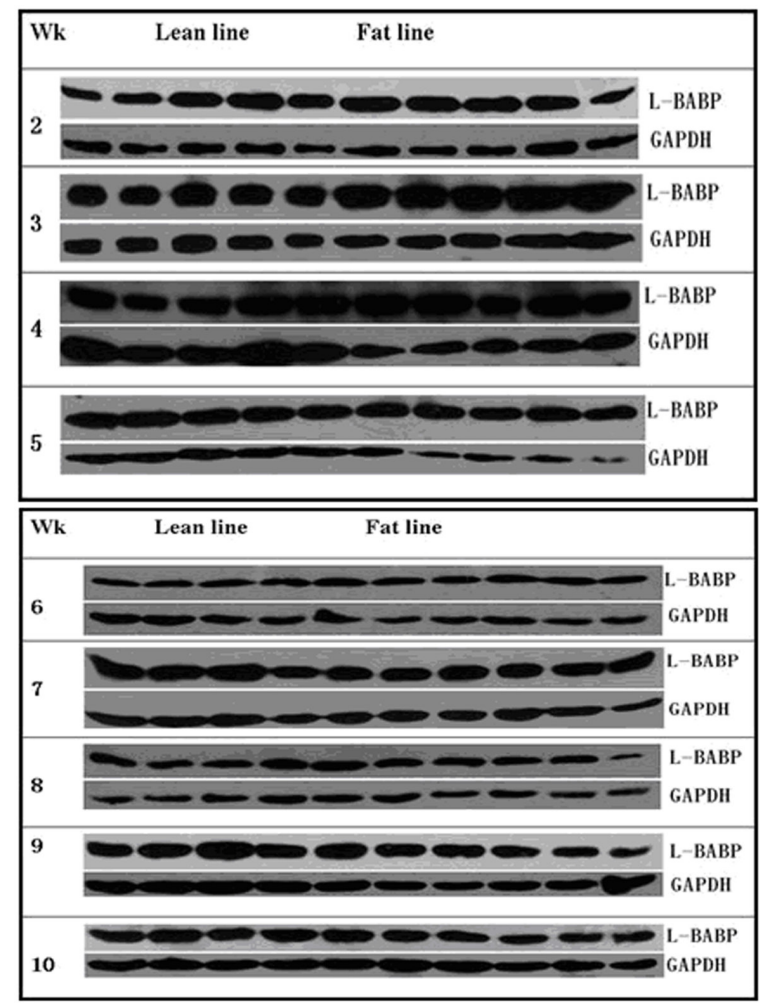

Figure 9. Western blot of liver bile acid-binding protein (L-BABP) expression in chicken liver tissues between fat and lean males for 11th generation population. $\mathrm{Wk}=$ week of age; GAPDH $=$ glyceraldehyde 3-phosphate dehydrogenase.

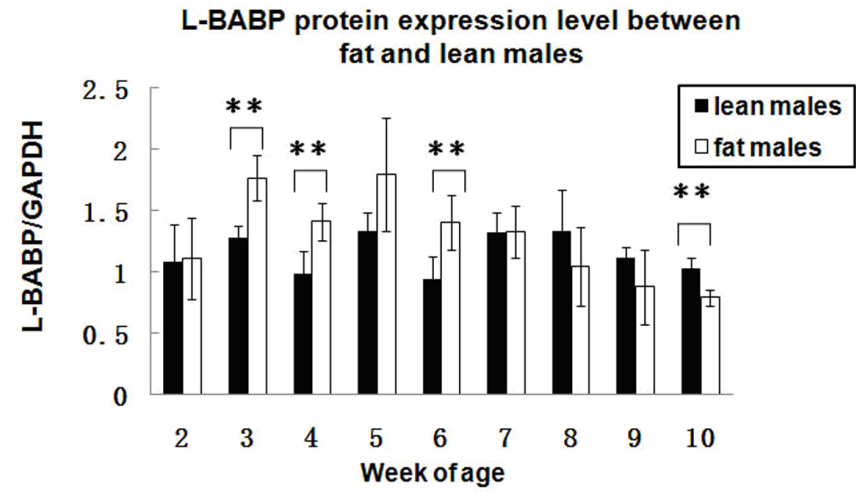

Figure 10. Analysis of liver bile acid-binding protein (L-BABP) in chicken liver tissues between fat and lean males for 11th generation population. Results are reported as means $\pm \mathrm{SD}(\mathrm{N}=5)$. ${ }^{*} \mathrm{P}<0.05$, significant difference. GAPDH = glyceraldehyde 3-phosphate dehydrogenase. 


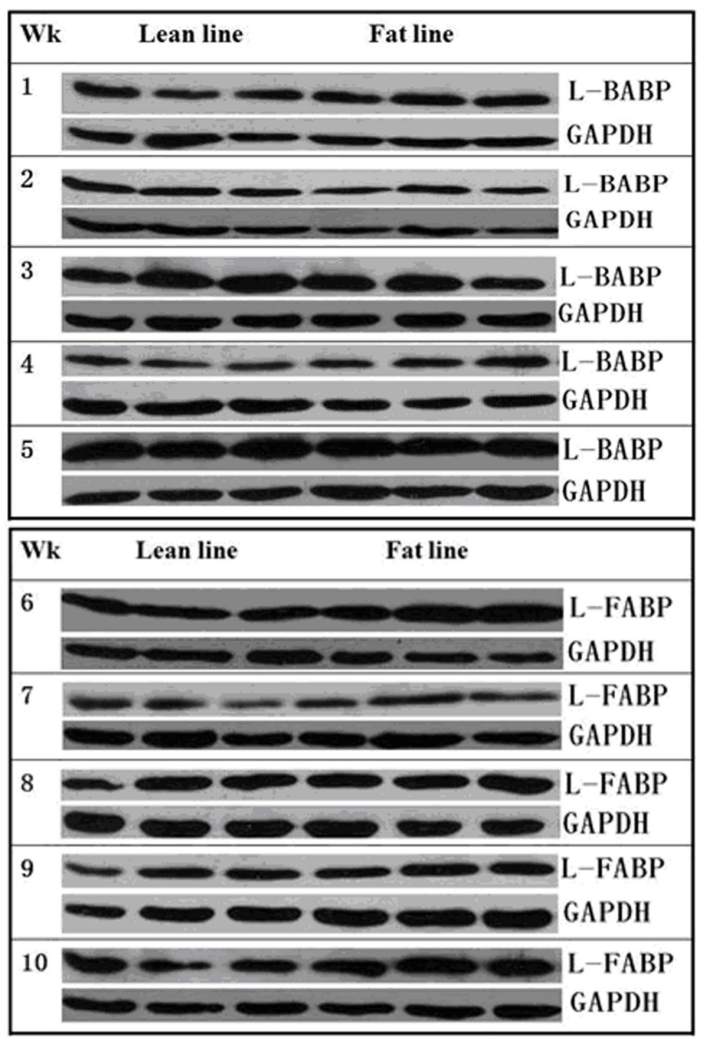

Figure 11. Western blot of liver bile acid-binding protein (L-BABP) expression in chicken liver tissues between fat and lean males for 14th generation population. $\mathrm{Wk}=$ week of age; $\mathrm{GAPDH}=$ glyceraldehyde 3-phosphate dehydrogenase.

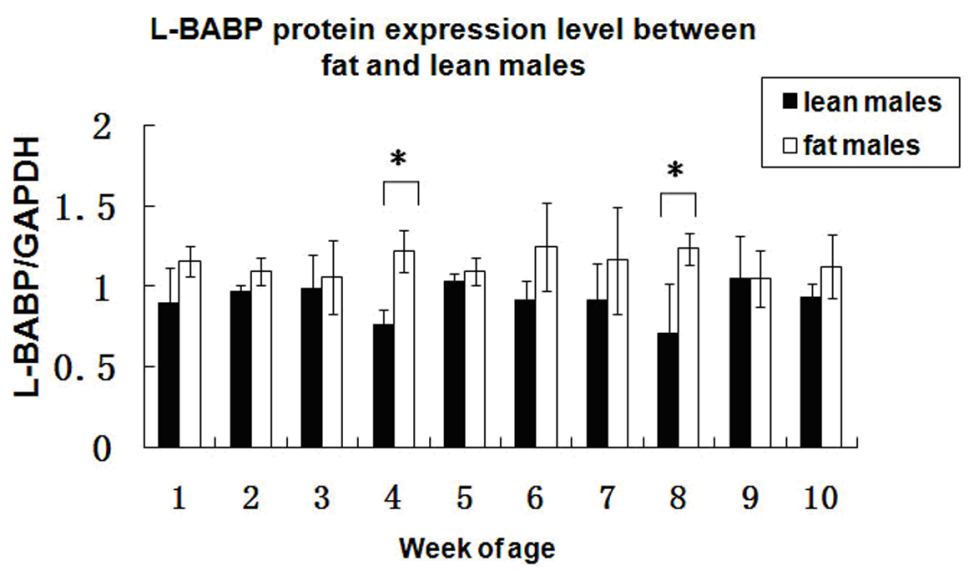

Figure 12. Analysis of liver bile acid-binding protein (L-BABP) in chicken liver tissues between fat and lean males for 14th generation population. Results are reported as means $\pm \mathrm{SD}(\mathrm{N}=3)$. $* \mathrm{P}<0.05$, significant difference. GAPDH $=$ glyceraldehyde 3-phosphate dehydrogenase . 


\section{L-BABP protein expression level between fat and lean males}

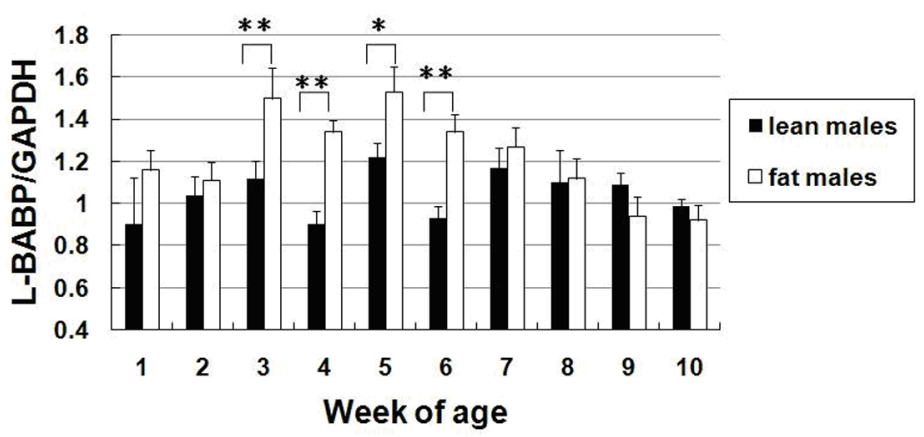

Figure 13. Analysis of liver bile acid-binding protein (L-BABP) in chicken abdominal fat tissues between fat and lean males for 11th and 14th generation population. Results are reported as means $\pm \mathrm{SD}(\mathrm{N}=8) .{ }^{*} \mathrm{P}<0.05$, significant difference. GAPDH = glyceraldehyde 3-phosphate dehydrogenase.

\section{DISCUSSION}

FABPs are members of a conserved multigene family that evolved over approximately one billion years by subsequent duplications of an ancestral gene, thereby generating a large number of tissue-specific homologs (Storch and Corsico, 2008). The FABP specific occurrence in certain tissues or cells possibly results from adaptation to specific cellular needs. In avian species, L-FABP and L-BABP are two types of intracellular lipid-binding proteins in the liver. Based on the $39 \%$ homology of amino acid sequences between chicken L-FABP and L-BABP (Murai et al., 2009), the specificities of the L-FABP and L-BABP antisera were tested by western blot analysis to avoid the presence of immune cross-reactivity between them. The result showed that each antiserum could recognize its corresponding protein, with no immunological cross-reaction. The antisera can therefore be used to detect the levels of L-FABP and L-BABP expression.

The result of our present study showed that there was significant difference between the fat and lean chickens in mRNA and protein expression levels of L-FABP in liver tissue. It was noted that there were significant differences of AFP between fat and lean male chickens from 2 to 10 weeks of age (Shi et al., 2010; Guo et al., 2011). The expression pattern of LFABP was consistent with the difference of the chicken abdominal deposition at most time points tested. Thus, the differential expression of L-FABP could be associated with fat deposition in the chicken. L-FABP has been hypothesized to be involved in liver lipid transport and lipoprotein metabolism. L-FABP null mice showed decreased fatty acid-binding capacity in the cytosol, which resulted in significantly reduced intracellular triacylglycerol deposition (Martin et al., 2003; Newberry et al., 2009). The transcription of the L-FABP gene and that of the microsomal triglyceride transfer protein, which is known to be required for hepatic verylow-density lipoprotein (VLDL) production and intestinal chylomicron synthesis, were both recently shown to be coordinately regulated by PPAR- $\alpha$. Involvement of L-FABP in hepatic VLDL production is suggested by the observation that L-FABP knockout prevents hepatic steatosis. This result also showed that ablation of the L-FABP gene decreases the synthesis of 
VLDL in liver (Spann et al., 2006). Therefore, we speculated that a high expression of chicken L-FABP in fat lines increases the rate of FA and VLDL synthesis and leads to abdominal fat mass deposition accordingly.

L-BABP is another intracellular lipid-binding protein in the chicken liver. L-BABP mRNA and protein are each only expressed in the liver, where cholesterol is divided into bile acids (Zhang et al., 2011). A recent study on the L-BABP crystal structure showed that L-BABP is more likely to function as a bile acid transporter than as a fatty acid transporter (Nichesola et al., 2004; Guariento et al., 2008). Bile acids play an important role in dietary fat digestion and absorption (Kramer et al., 1998). Our results clearly showed that there was higher L-BABP protein and mRNA expression in the fat line than in the lean line. We speculate that a high L-BABP expression in the fat line could increase dietary fat absorption through regulating bile acid transport and ultimately lipogenesis and deposition.

The difference of abdominal deposition between fat and lean chickens showed a rapid upward trend at 2 to 6 weeks of age for the 11th generation, and at 1 to 5 weeks of age for the 14th generation population. Interestingly, the difference in expression of the two genes was mainly during these periods, whether of mRNA or protein. Thus, we speculate that the two genes are very important for chicken lipid metabolism. However, the result of our present study showed that there was significant difference in AFP between fat and lean chickens between 2 and 10 weeks of age, but the difference at the other times was not significant between the fat and lean male chickens. In other words, the difference between L-FABP and L-BABP expressions and AFP is inconsistent at some time points tested. In fact, lipogenesis and deposition are complicated processes that are related to multiple genes and pathways. The results of the chicken liver tissue expression profile revealed that many genes involved in FA transport and degradation, such as Apo-AI, PPAR- $\gamma$, APOVLDL-II lipoprotein, and the FABP family, were differentially expressed in liver tissue between fat and lean lines (Wang et al., 2010). L-FABP and L-BABP probably only make a partial contribution to the deposition of abdominal fat tissue. In the current study, the mRNA expression levels of L-FABP and L-BABP in liver tissue were not accompanied overall by parallel changes in their protein expression level. We presume that the expressions of chicken L-FABP and L-BABP are related with posttranscriptional modification.

In summary, our study confirmed that there is significant differential expression of chicken L-FABP and L-BABP between fat and lean chickens. The possible mechanism of LFABP-regulated abdominal fat deposition is that a high expression of L-FABP induces a high rate of FA and VLDL synthesis and leads to an increased abdominal fat mass accordingly. High L-BABP expression in the fat line could increase dietary fat absorption and ultimately lipogenesis and deposition. However, the precise mechanisms by which L-FABP and L-BABP regulate the development and growth of chicken abdominal fat tissue need to be investigated further.

\section{ACKNOWLEDGMENTS}

The authors gratefully acknowledge the members of the Poultry Breeding Group of the College of Animal Science and Technology in the Northeast Agricultural University for help in managing the birds and collecting the data. Research supported by the National Natural Science Funds (\#30972087), the Program for Innovation Research Team in University of Heilongjiang Province (\#2010td02), and the China Agriculture Research System (\#CARS-42). 


\section{REFERENCES}

Atshaves BP, McIntosh AM, Lyuksyutova OI, Zipfel W, et al. (2004). Liver fatty acid-binding protein gene ablation inhibits branched-chain fatty acid metabolism in cultured primary hepatocytes. J. Biol. Chem. 279: 30954-30965.

Atshaves BP, McIntosh AL, Payne HR, Mackie J, et al. (2005). Effect of branched-chain fatty acid on lipid dynamics in mice lacking liver fatty acid binding protein gene. Am. J. Physiol. Cell Physiol. 288: C543-C558.

Beringhelli T, Goldoni L, Capaldi S, Bossi A, et al. (2001). Interaction of chicken liver basic fatty acid-binding protein with fatty acids: a 13C NMR and fluorescence study. Biochemistry 40: 12604-12611.

Capaldi S, Guariento M, Perduca M, Di Pietro SM, et al. (2006). Crystal structure of axolotl (Ambystoma mexicanum) liver bile acid-binding protein bound to cholic and oleic acid. Proteins 64: 79-88.

Ceciliani F, Monaco HL, Ronchi S, Faotto L, et al. (1994). The primary structure of a basic (pI 9.0) fatty acid-binding protein from liver of Gallus domesticus. Comp. Biochem. Physiol. B Biochem. Mol. Biol. 109: 261-271.

Córdoba OL, Sanchez EI and Santome JA (1999). The main fatty acid-binding protein in the liver of the shark (Halaetunus bivius) belongs to the liver basic type. Isolation, amino acid sequence determination and characterization. Eur. $J$. Biochem. 265: 832-838.

Denovan-Wright EM, Pierce M, Sharma MK and Wright JM (2000). cDNA sequence and tissue-specific expression of a basic liver-type fatty acid binding protein in adult zebrafish (Danio rerio). Biochim. Biophys. Acta 1492: 227-232.

Di Pietro SM, Dell'Angelica EC, Schleicher CH and Santome JA (1996). Purification and structural characterization of a fatty acid-binding protein from the liver of the catfish Rhamdia sapo. Comp. Biochem. Physiol. B Biochem. Mol. Biol. 113: 503-509.

Di Pietro SM, Veerkamp JH and Santome JA (1999). Isolation, amino acid sequence determination and binding properties of two fatty-acid-binding proteins from axolotl (Ambistoma mexicanum) liver. Evolutionary relationship. Eur. J. Biochem. 259: 127-134.

Di Pietro SM, Corsico B, Perduca M, Monaco HL, et al. (2003). Structural and biochemical characterization of toad liver fatty acid-binding protein. Biochemistry 42: 8192-8203.

Gao N, Qu X, Yan J, Huang Q, et al. (2010). L-FABP T94A decreased fatty acid uptake and altered hepatic triglyceride and cholesterol accumulation in Chang liver cells stably transfected with L-FABP. Mol. Cell Biochem. 345: 207-214.

Gordon JI, Elshourbagy N, Lowe JB, Liao WS, et al. (1985). Tissue specific expression and developmental regulation of two genes coding for rat fatty acid binding proteins. J. Biol. Chem. 260: 1995-1998.

Griffin HD, Guo K, Windsor D and Butterwith SC (1992). Adipose tissue lipogenesis and fat deposition in leaner broiler chickens. J. Nutr. 122: 363-368.

Guariento M, Raimondo D, Assfalg M, Zanzoni S, et al. (2008). Identification and functional characterization of the bile acid transport proteins in non-mammalian ileum and mammalian liver. Proteins 70: 462-472.

Guo L, Sun B, Shang Z, Leng L, et al. (2011). Comparison of adipose tissue cellularity in chicken lines divergently selected for fatness. Poult. Sci. 90: 2024-2034.

He J, Chen J, Lu L, Tian Y, et al. (2012). A novel SNP of liver-type fatty acid-binding protein gene in duck and its associations with the intramuscular fat. Mol. Biol. Rep. 39: 1073-1077.

Hertzel AV and Bernlohr DA (2000). The mammalian fatty acid-binding protein multigene family: molecular and genetic insights into function. Trends Endocrinol. Metab. 11: 175-180.

Jordal AE, Hordvik I, Pelsers M, Bernlohr DA, et al. (2006). FABP3 and FABP10 in Atlantic salmon (Salmo salar L.) general effects of dietary fatty acid composition and life cycle variations. Comp Biochem. Physiol. B Biochem. Mol. Biol. 145: 147-158.

Ko YH, Cheng CH, Shen TF and Ding ST (2004). Cloning and expression of Tsaiya duck liver fatty acid binding protein. Poult. Sci. 83: 1832-1838.

Kramer W, Corsiero D, Friedrich M, Girbig F, et al. (1998). Intestinal absorption of bile acids: paradoxical behaviour of the $14 \mathrm{kDa}$ ileal lipid-binding protein in differential photoaffinity labelling. Biochem. J. 333: 335-341.

Martin GG, Danneberg H, Kumar LS, Atshaves BP, et al. (2003). Decreased liver fatty acid binding capacity and altered liver lipid distribution in mice lacking the liver fatty acid-binding protein gene. J. Biol. Chem. 278: 21429-21438.

Martin GG, Atshaves BP, McIntosh AL, Mackie JT, et al. (2006). Liver fatty acid binding protein gene ablation potentiates hepatic cholesterol accumulation in cholesterol-fed female mice. Am. J. Physiol. Gastrointest. Liver Physiol. 290: G36-G48.

Martin GG, Atshaves BP, McIntosh AL, Payne HR, et al. (2009). Liver fatty acid binding protein gene ablation enhances age-dependent weight gain in male mice. Mol. Cell Biochem. 324: 101-115.

Murai A, Furuse M, Kitaguchi K, Kusumoto K, et al. (2009). Characterization of critical factors influencing gene expression of two types of fatty acid-binding proteins (L-FABP and Lb-FABP) in the liver of birds. Comp. Biochem.

Genetics and Molecular Research 12 (4): 4192-4206 (2013)

CFUNPEC-RP www.funpecrp.com.br 
Physiol. A Mol. Integr. Physiol. 154: 216-223.

Newberry EP, Kennedy SM, Xie Y, Luo J, et al. (2009). Diet-induced alterations in intestinal and extrahepatic lipid metabolism in liver fatty acid binding protein knockout mice. Mol. Cell Biochem. 326: 79-86.

Nichesola D, Perduca M, Capaldi S, Carrizo ME, et al. (2004). Crystal structure of chicken liver basic fatty acid-binding protein complexed with cholic acid. Biochemistry 43: 14072-14079.

Norris AW and Spector AA (2002). Very long chain n-3 and n-6 polyunsaturated fatty acids bind strongly to liver fatty acid-binding protein. J. Lipid Res. 43: 646-653.

Sams GH, Hargis BM and Hargis PS (1991). Identification of two lipid binding proteins from liver of Gallus domesticus. Comp. Biochem. Physiol. B 99: 213-219.

Schievano E, Quarzago D, Spadon P, Monaco HL, et al. (1994). Conformational and binding properties of chicken liver basic fatty acid binding protein in solution. Biopolymers 34: 879-887.

Sewell JE, Davis SK and Hargis PS (1989). Isolation, characterization, and expression of fatty acid binding protein in the liver of Gallus domesticus. Comp. Biochem. Physiol. B 92: 509-516.

Shi H, Wang Q, Wang Y, Wang N, et al. (2008). Preparation of antiserums against chicken liver-type fatty acid binding protein (L-FABP) and tissue expression analyses of L-FABP. Acta Vet. Zootec. Sin. 39: 1466-1469.

Shi H, Wang Q, Zhang Q, Leng L, et al. (2010). Tissue expression characterization of chicken adipocyte fatty acid-binding protein and its expression difference between fat and lean birds in abdominal fat tissue. Poult. Sci. 89: 197-202.

Spann NJ, Kang S, Li AC, Chen AZ, et al. (2006). Coordinate transcriptional repression of liver fatty acid-binding protein and microsomal triglyceride transfer protein blocks hepatic very low density lipoprotein secretion without hepatosteatosis. J. Biol. Chem. 281: 33066-33077.

Storch J and Corsico B (2008). The emerging functions and mechanisms of mammalian fatty acid-binding proteins. Annu. Rev. Nutr. 28: 73-95.

Wang HB, Wang QG, Zhang XY, Gu XF, et al. (2010). Microarray analysis of genes differentially expressed in the liver of lean and fat chickens. Animal 4: 513-522.

Wang Q, Li H, Li N, Leng L, et al. (2006). Tissue expression and association with fatness traits of liver fatty acid-binding protein gene in chicken. Poult. Sci. 85: 1890-1895.

Wolfrum C, Borrmann CM, Borchers T and Spener F (2001). Fatty acids and hypolipidemic drugs regulate peroxisome proliferator-activated receptors alpha - and gamma-mediated gene expression via liver fatty acid binding protein: a signaling path to the nucleus. Proc. Natl. Acad. Sci. U. S. A. 98: 2323-2328.

Zhang Q, Shi H, Ding N, Wang Y, et al. (2011). Antiserums preparation and tissue expression analyses of chicken liver bile acid binding protein (LBABP). J. Agric. Biotechnol. 19: 571-576. 